Deviant Sexual Behaviour: By John Bancroft. (Pp $233 £ 5.00$ net). Clarendon Press: Oxford University Press, Oxford: 1974.

This book, from one of the foremost British researchers into sexual behaviour sets out to review behavioural treatment techniques available for such deviations as homosexuality, transvestism, exhibitionism, sado-masochism and paedophilia.

Bancroft precedes the main tract with an historical perspective of deviant sexuality, noting the distinction between 'matrist' societies, in which attitudes to homosexuality (cf incest) are believed to be permissive, and 'patrist' societies for which the converse is true. $\mathrm{He}$ also reviews briefly the contrast in medical opinion between those who see sexual deviation as something acquired through learning and those who deem it an innate anomaly or the consequence of some degenerative process: this polarization continues today. Feldman and MacCulloch embrace both points of view in making a distinction between 'primary' and 'secondary' homosexuals, the former marked by an absence of previous heterosexual fantasy and activity and carrying a much poorer prognosis: although their views are difficult to reconcile with the work of Money Hampson and Hampson, who found that sex of assignment and rearing were a more reliable prognostic indicator of future sexual identity than chromosomal, gonadal, hormonal, or morphological sex.

The two basic treatment techniques available for sexual deviants are aversion therapy and desensitization. In aversion therapy, the patient is presented with some stimulus associated with the deviant activity - it may be a picture or slide, a verbal description, or a fantasy which the patient himself provides. Following stimulus onset, some noxious stimulus occurs. This usually consists of an electric shock administered from a batterypowered transformer via a cuff electrode. In some studies, the patient is given the option of avoiding or terminating the shock by switching off the deviant stimulus. Theoretically anxiety engendered by shock threat then becomes associated with the deviant stimulus, whilst the shock also, according to McGuire, neutralizes pleasurable feelings associated with the deviant activity. Bancroft, in a chapter which makes heavy reading, compares the various alternative rationales with the actual results. Follow-up data on aversion therapy yield differing reported rates of success. Of patients consenting to treatment, between one quarter and two-thirds remain improved after follow-up periods varying between three months and eight years. Differing groups of therapists report different success rates, which might be due to a number of factors, ranging from patient selection to procedural differences in treatment, to differences in criteria for improvement (usually a combination of self-report behavioural data and measurements of attitude change).

However, aversion therapy administered in isolation is rarely as effective as when it is combined with attempts to tutor the patient in patterns of heterosexual interaction. There appears to be an identifiable group of sexual deviants who are afraid or anxious in heterosexual situations. It is possible to treat this in the same way as one would a phobia, by training the patient to relax whilst imagining a carefully graduated series of scenes involving heterosexual interaction. The patient is encouraged to practise dating behaviour and so to 'desensitize' himself to his anxieties about women by repeated exposure to these situations. Hierarchies, as these graduated series of scenes are called, can also be constructed for explicit sexual, as opposed to social heterosexual, behaviour.

Behavioural treatments attract the full ire of the deviant subculture. Crediting these methods with more efficacy than many practitioners would claim, homosexual spokesmen accuse therapists of 'brainwashing' and stress that homosexuality is not an illness (whatever 'illness' means). They argue that doctors have come into contact with only a dissatisfied minority, and point out that many heterosexuals are also maladjusted. But it is of little immediate consolation to a patient that social attitudes towards homosexuality are gradually changing. By what standard, furthermore, is it ethical to withhold powerful treatments from patients in distress? In addition, I know of no behaviour therapist in Britain who is currently applying compulsory treatment to recalcitrant homosexual patients. Apart from ethical considerations, it is simply not cost effective to do so.

A thornier problem is presented by deviant behaviour of the 'individual' type, such as paedophilia or exhibitionism, as contrasted with the subcultural. Bancroft unfortunately devotes little space to them. But they are the very patients for whom treatment is liable to be made compulsory, eg, as a condition of probation. There are two aspects to this. The patient has the option of refusing treatment, although to do so might attract a relatively severer sentence. Secondly, and more problematically, he may consent to treatment as a 'soft option'. That is to say, he may have no intention of altering his sexual behaviour whilst maintaining a pretence of cooperation in treatment. Bancroft cites an example of such a case. One solution might be to offer treatment on a voluntary basis following acquittal or conviction and sentencing, so that legal coercion is minimized.

In general, this book is to be highly commended for its quality of academic content. Therein lies a 
weakness, however, for a person unfamiliar with the field might find a number of passages fairly difficult to follow. For this reason, I think that a short summary could usefully have been appended to certain chapters, notably chapter 5, but Bancroft deserves every credit for having pulled together in a coherent way the therapy literature in that most thorny area of clinical intervention, deviant sexual behaviour.

RONALD C LYLE

\section{The Ethics of Foetal Research}

By Paul Ramsey. (Pp I04, cloth $£ 4.00$, paperback $£_{1.50)}$. Yale University Press 1975.

Paul Ramsey presents a complicated review of the ethical documents relating to fetal research produced in America by the National Institute of Child Health and Human Development and the National Institute of Health and compares these with the regulations drawn up in Great Britain under an advisory group chaired by Sir John Peel. He outlines types of fetal research now being done and examines their potential benefits. He follows the history of the way in which these reports came into being and some of the controversies which surrounded them. He then applies some ethical questions to various sections of the reports.

Without having the complete text of the reports the result is somewhat confusing. One may even find his approach to the subject lacking in any logical formulation. However, this book is of great importance to those who are considering the problem of the abortion laws and the difficulties which these present for the whole question of fetal research. The fact that this area has needed examination would seem to have flowed from the new legal situation on abortion. If the fetus is no longer deemed human, and has already been condemned, then what is to prevent it being used for research? As Paul Ramsey himself says, 'Far from abortion settling the question of fetal research, it could be that sober reflection on the use of the human fetus in research could unsettle the abortion issue.' All the committees considering this problem were faced with the fundamental problem of defining the legal status of the fetus, 'an entity too alive to be dead, not mature enough to be a viable baby, yet human enough to be specially protectable'. As the author points out, they sought for their ethical norms 'all appropriate procedures providing protection for children as subjects in bio-medical research'. At no time was this problem viewed in the light of the examination of the ethics in regard to a corpse, still less to that of an animal. In America Congress reviewed the problem under its policy for 'the protection of human subjects' and was referred to the Commission for the Protection of Human Subjects in Biomedical and Behavioural Research.

The research itself included the question of such procedures as seeing what damage various illnesses that the mother might have would do to the fetus, bearing in mind that the fetus was already condemned to death, and examining the possibility of trial resuscitation measures on an almost viable fetus which might later be of value to other spontaneous abortions. In the latter case the problem arose as to what might be done if such resuscitation measures began to have a positive effect. It seemed that at that point, just when measures were having a beneficial effect on the fetus, they would have to be stopped as the fetus had already been condemned to death. As will be seen from these two examples the book is not really intended for those with a delicate stomach. At the same time this work should not escape the notice of those who are concerned at this present time in the debate on abortion. Paul Ramsey asks whether some of the motivation for such research has not in itself grown within the healing professions out of a sense of guilt: 'The wastage of unborn lives needs redemption; something must be saved from it. The research gains promise not only benefits; they can also rectify and do at least something to redeem the destruction we are collectively causing in pursuit of other social and personal goods.' It is perhaps this motivation which is behind the recommendations of the Human Embryology and Development and Study Section of the National Institute of Child Health and Human Development to the effect that 'planned scientific studies of the human fetus must be encouraged and that acceptable formats and safeguards must be found "Tा While such comments have beef. made in respect of criminals whọ? are awaiting execution, where some of their redemption might be? brought about by permitting theme selves to be used experimentally, the innocent fetus can hardly be in nee बन of such redemption nor give consen to it.

The moral and ethical examination which this book gives to the wholf subject seems most acceptable, and asks for study by those who might bظ involved in this form of research. TQ others it may be of some interest and to all who are concerned with the way in which moral decisions are created and enter into the law of the land this book may well be revelation.

LOUIS MARTEAU 